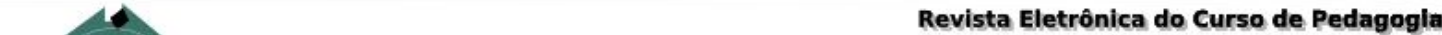 do Campus Jatai - UFG

\section{Formação, currículo e ensino de graduação}

\author{
Simone Alexandre Martins Corbiniano*
}

\section{Resumo}

O ensino na universidade tem enfatizado cada vez mais em seus currículos as necessidades do mercado de trabalho e do desenvolvimento econômico e tecnológico. Contudo, é preciso empenhar-se no diálogo acerca da formação do cidadão e, em especial, do educador valorizando os nexos que constituem essa formação como processo mais amplo, não restrito à formação profissional. Ao situar a questão da formação na atualidade, cabe lembrar o sentido humano, cultural e histórico que a instituição universitária logra na sociedade. Decorrente desse sentido, o ensino de graduação deve voltar-se não somente ao desenvolvimento de habilidades que possibilitem às pessoas participarem da dimensão econômica da sociedade, mas, sobretudo, à formação comprometida com a busca do saber, a criação e a crítica. Esses princípios são indispensáveis à formação dos sujeitos em sua totalidade humana.

Palavras-chave: Educação, formação profissional, formação humana.

\section{Formation, curriculum and graduation teaching}

\begin{abstract}
The teaching at the university has increasingly emphasized, in its curriculum the needs of the labor market and of the economic and technologic development. Although, we need to engage in dialogue about the citizen training in general and, in particular, of the educator, valorizing the links that form this training as a wider process, not restricted to the professional training. In situating the training in actuality, it is necessary to remind the human, cultural and historic sense that the university achieves in society. Due to this sense, the graduation teaching must return not only to develop skills that enable people to participate in the economic dimension of the society but, mostly, to the training institute compromised to the search of knowledge, the creation and criticism. These principles are essential to the formation of subjects in its human entirety.
\end{abstract}

Keywords: Education, professional formation, human formation.

\footnotetext{
* Mestre em educação, professora do curso de Pedagogia da Terra da Faculdade de Educação/UFG.
} 
Os cursos de formação na universidade assim como o público que os procuram têm dado maior ênfase às necessidades do mercado de trabalho, contudo é importante interrogar questões subjacentes a essa formação, pois o cidadão em geral, e em especial o educador, constitui-se de diversas dimensões que estão ligadas a processos formativos mais amplos e não restritos à formação profissional.

$\mathrm{Na}$ atualidade a idéia de cidadania tornou-se inseparável de todos os debates e projetos da área da educação, contudo, é um problema o fato de que a cidadania tanto quanto a educação têm sido cada vez mais compreendidas de modo restrito como acesso à escola para munir-se de potencialidades que possibilite às pessoas participarem da dimensão econômica da sociedade. Conceber a educação e a cidadania desse modo, não só restringe o sentido das instituições educativas como a escola e a universidade, mas também reduz o papel da educação como cultura e formação integral do homem. Essa realidade cultural introduz a cidadania no vazio social em que ela é muito citada e pouco compreendida e realizada, até mesmo dentro da universidade.

A universidade desde sua origem na Idade Média tem construído, não sem contradições, as referências históricas que a torna uma instituição inseparável das idéias de formação e cidadania. Como defende Marilena Chaú́, "a universidade sempre foi uma instituição social, isto é, uma ação social, uma prática social fundada no reconhecimento público de sua legitimidade e de suas atribuições, num princípio de diferenciação, que lhe confere autonomia perante outras instituições sociais" (1999) Caminho histórico, que lhe conferiu o compromisso com o saber, a reflexão, a criação e a crítica. Princípios esses que o ensino de graduação dentro de suas possibilidades, não deve furtar-se a realizar na formação das pessoas.

É preciso conceber a formação acadêmica como instância capaz de transcender à instrução e a capacitação, de modo a cultivar permanentemente no ensino de graduação as condições próprias para formar também o sujeito em sua totalidade. Empenhando-se em discutir o sentido da formação humana, Ildeu Coêlho esclarece que

\footnotetext{
a desvalorização e a desqualificação das humanidades comprometem o presente e o futuro da humanidade, ao condenar o homem à esfera do imediato, da produção, do pragmático, do prático, e ao negar às crianças jovens e adultos o convívio com as formas de sensibilidade, do pensamento, da contestação e da expressão e com projetos de transformação. Sem essas realidades é impensável a existência humana, a sociedade e a história. [...] Acresce-se a isso a excessiva preocupação com o imediato, o útil, o prático, o mercado e o consumo; a supervalorização da prática em detrimento da teoria, da experiência e da prática como decisivas na formação profissional, da experiência, do quotidiano e da prática como fundamentais na
} 
formação dos educadores; e o imaginário que privilegia a educação pela vida, em detrimento da escola, dos livros, da teoria. Eis sintomas e expressões do irracionalismo e da anticultura (2003, p. 2).

Nesse sentido é preciso questionar a formação acadêmica que passa cada vez mais a sedimentar-se em uma finalidade útil. Nela, a ciência e a técnica são subsídios para humanizar e emancipar pessoas? Como poderá sê-lo em cursos de graduação que não cultivam em seus currículos o valor da leitura e da reflexão? Essas e tantas outras questões que constituem enorme desafio, levando ao incômodo e à aspiração de pôr a formação das pessoas em questão, especialmente na universidade.

A história do ensino na universidade brasileira é marcada por episódios de transgressão e resistência política em nome de causas históricas no cultivo da autonomia acadêmica, postura louvável diante do atual conformismo que permeia a academia. Edificado na tensão entre o instituído e o instituinte, o ensino de graduação "expressa as complexas e contraditórias relações que constituem a sociedade da qual emerge" (Coêlho, 1994, p. 18).

Surgidas em grande parte das necessidades e metamorfoses do capitalismo, as políticas públicas para o ensino superior atualmente estão sintonizadas com a orientação e avaliação dos organismos transnacionais que pautam, ainda que indiretamente, os projetos e a regulamentação do ensino de graduação. Compreendendo nesse contexto o currículo acadêmico, como espaço de luta hegemônica entre diferentes blocos de poder político, econômico e cultural; mais difícil é vislumbrar em que medida a realização da hegemonia pode dar primazia aos interesses genuinamente sociais e humanos na construção desses currículos.

Tais questões da formação contemporânea ganham indispensáveis esclarecimentos nas reflexões de Gramsci, que ao discutir um possível projeto de nação soberana para a Itália do início do século XX, elucida acerca das forças políticas do liberalismo que convergiram, no caso da educação, em tendências de aligeiramento da formação e difusão da profissionalização (2000, p. 15-53).

A ênfase no aprender a fazer e no caráter de qualificação e competência tem se constituído no mote dos diversos contextos da educação escolar, enfatizando a necessidade de promover mudanças nas estruturas da educação para que ela possa acompanhar as demandas das relações de produção e consumo na sociedade. É expressivo o movimento que se estabelece nos sistemas de ensino como coadjuvantes do capitalismo, a tendência é distanciar a educação escolar do que se pode chamar de formação clássica, e aproximá-la cada vez mais da informação, da técnica, da diversidade de modalidades de formação para o trabalho. 
Como expressão dessas tendências o atual contexto dos cursos de graduação tem legitimado os princípios de uma formação pragmática, que aprimora as pessoas tornando-as mais adaptados ao imediato e à esfera da aplicabilidade. Fechada sobre si mesma, essa forma de conceber a academia ignora que toda formação "tem sentido unicamente como educação dirigida a uma auto-reflexão crítica" (Adorno, 1995, p. 121). É essa reflexão que leva ao reconhecimento dos mecanismos de exploração e violência aos quais muitas vezes as pessoas se entregam irracionalmente em detrimento de uma sociabilidade que seja sedimentada no diálogo, na justiça, princípios esses, que deveriam ser compreendidos e cultivados em todos os níveis de ensino.

Haja vista a importância que a escola em geral tem na sociedade, ela precisa ser discutida não apenas em termos do que se deve ensinar mas, sobretudo, para quais caminhos ela tem conduzido as pessoas. Duas questões diferentes, tanto quanto inseparáveis. Primeiro, quanto ao que se deve ensinar nos currículos escolares, espera-se que não sejam simples conteúdos de socialização do conhecimento. É preciso valorizar o encontro formativo entre o estudante e o professor por meio da escola, da universidade, propiciando um ensino que seja provocativo para o intelecto, a criação, a lucidez. Quanto à segunda questão, dos caminhos para os quais a formação pode conduzir, cabe lembrar que todo o sentido da educação reside em seu fim. Qual o fim da educação escolar? Levar as letras às pessoas, os diplomas? Mais que isso, cabe voltar o olhar para os princípios que os homens podem e devem encontrar nas escolas, questões que formam um caráter auto-crítico e incorruptível no homem.

Para isso, dizer que a formação nos cursos de graduação precisa ser de qualidade já não corresponde a dizer o suficiente, pois nesse contexto a idéia de qualidade pode ter sentido muito relativo. Entretanto, sem a pretensão de atribuir à formação um sentido absoluto, podese compreendê-la a princípio, como realidade instituinte da qual somos obreiros capazes de edificar sob outros conceitos e formas, pois se

realiza essa formação da qual estamos falando à medida que cultiva a dúvida, o estudo, a racionalidade, a reflexão, a crítica, a contestação, a busca sempre retomada da verdade, o rigor e a radicalidade no pensar, a imaginação e a sensibilidade; ao realizar a iniciação crítica de jovens e adultos no universo das ciências, da tecnologia, da filosofia, das letras, das artes, enfim, no universo da cultura [...]. O que a justifica, portanto, é a formação de pessoas que pensem as idéias e a prática e ajam como seres humanos (Coêlho, 2004, p. 46).

Assumir tal postura crítica diante da formação acadêmica significa compreender o valor e a amplitude do ensino de graduação como instância formadora de pessoas capazes de contestar relações autoritárias e coorporativas na sociedade, fazendo a recusa de realidades e 
valores estabelecidos, reconhecendo as possibilidades de construir a sociedade de outro modo, compreendendo as determinações histórico-sociais que a envolve.

Por outro lado, o caráter de especialização e burocratização na organização da cultura e nas concepções educativas, de acordo com Gramsci, é expressão da formação que faz a separação entre o pensar e o fazer, pois, "a divisão fundamental da escola em clássica e profissional era um esquema racional: a escola profissional destinava-se às classes instrumentais, enquanto a clássica destinava-se a classes dominantes e aos intelectuais" (2000, p. 33).

Situando essa cisão como um problema presente e buscando distinguir os princípios demandados pela educação na sociedade capitalista, Gramsci retoma os valores do ensino clássico, chamado por ele também de velha escola ${ }^{1}$. Nela

\begin{abstract}
o estudo gramatical das línguas latina e grega, unido ao estudo das literaturas e histórias políticas respectivas, era um princípio educativo na medida em que o ideal humanista, que se personifica em Atenas e Roma, era difundido em toda a sociedade [...]. As noções singulares não eram aprendidas com vistas a uma imediata finalidade prático-profissional: tratava-se de algo desinteressado, pois o que contava era o desenvolvimento interior da personalidade, a formação do caráter através da absorção e da assimilação de todo o passado cultural [...]. Não se aprendia o latim e o grego para falá-los, para trabalhar como garçom, intérprete ou correspondente comercial. Aprendia-se para conhecer diretamente a civilização dos dois povos, pressuposto necessário da civilização moderna, isto é, para ser e conhecer conscientemente a si mesmo. (2000, p. 46).
\end{abstract}

Ecos dessa formação podem ser notados até a passagem para o século XX, subsistindo em concepções e sistemas educativos isolados e considerados anacrônicos em relação às crescentes exigências produtivas da sociedade capitalista. Embora originariamente instituída para a classe burguesa, a escola clássica declinou, paradoxalmente, nas metamorfoses desse mesmo sistema burguês. A formação escolar no contexto da modernidade tem seus fundamentos marcados pela paulatina degenerescência das categorias da educação medieval e antiga, e pela perda do ideal de humanização a elas subjacente. O princípio da autonomia na acepção kantiana, intrínseco aos valores do humanismo iluminista, também se perderam posteriormente, frente a outras necessidades da sociedade capitalista contemporânea. Emergiu desse caminho histórico a formação voltada à racionalidade tecnocientífica, necessariamente mais fragmentada, auto-referente.

Ao criticar essa contextura, Horkheimer e Adorno compreendem que só há constituição social e conseqüentemente formação, na medida em que a relação entre os

\footnotetext{
${ }^{1}$ A velha escola nesse contexto refere-se à formação humanista da escola clássica, que consiste em uma educação em sentido mais amplo referida à cultura geral (Cf. Gramsci, 2000, p. 15-53).
} 
homens é mediada ou institucionalizada, do mesmo modo que as instituições nada mais são que "epifenômenos do trabalho vivo dos homens" (1973, p. 32), questão que se aproxima da concepção hegeliana de que "a satisfação das necessidades individuais só é possível, para cada indivíduo, mediante a dependência geral e recíproca; e a satisfação das suas necessidades é um trabalho de todos" (Hegel apud Horkheimer e Adorno, 1973, p. 33). Por isso, é preciso lembrar que para além da escola há a educação afirmada pelas instituições como a família, a mídia, a religião, os movimentos sociais, a arte, e outros que também são bases da formação das pessoas na sociedade, e como tais são impregnadas de valores culturais, constituem e são constituídas por princípios, interesses e ações intervenientes na sociedade. A educação comprometida com os processos de humanização e formação do sujeito em sua totalidade é obra para todas as instâncias da sociedade, pois a consciência dos homens é expressão da

\begin{abstract}
fração de sociedade civil da qual participa, das relações sociais tais como elas se concentram na família, na vizinhança, na aldeia. [...] nos quadros de uma cultura fossilizada e anacrônica, não existe unidade entre escola e vida e, por isso, não existe unidade entre instrução e educação. Por isso, pode-se dizer que, na escola, o nexo instrução-educação somente pode ser representado pelo trabalho vivo do professor. Se o corpo docente é deficiente esse nexo é abandonado, visando a resolver questões do ensino de acordo com esquemas abstratos nos quais se exalta a educatividade, a obra do professor se tornará ainda mais deficiente: ter-se-á uma escola retórica, sem seriedade, pois faltará a corposidade material do certo e o verdadeiro será verdadeiro só verbalmente, ou seja, de modo retórico (Gramsci, 2000, p. 44).
\end{abstract}

Como face inseparável das instituições sociais e seu substrato, o ensino na universidade logra comprometimento específico, espera-se dele não só a possibilidade de discutir e fazer a crítica da formação no âmbito da própria universidade e das instituições em geral, mas também de formar o homem em sua visão de mundo, dar-lhe meios conscientes e críticos para suas ações na sociedade. Tornar evidente a tensão entre o instituído e o que pode e deve ser criado e recriado com vistas a mudanças também integra o quadro de possibilidades do ensino de graduação que afirma-se como educação comprometida com a humanidade, e nesse sentido, reconstitui o nexo instrução-educação, como alerta Gramsci (2000, p. 42-47) em seus estudos sobre os riscos da escola puramente profissional .

Cada vez mais, os valores da reflexão e da formação de sujeitos políticos e culturais são deslocados ou suprimidos diante da aquisição de habilidades que possam tornar o individuo apto à interação produtiva na sociedade. Busca-se nesse caso a capacidade de tomar decisões fundamentais, e continuar aprendendo diante das rápidas transformações sociais. Ainda que tal formação leve "em conta mais o desenvolvimento das capacidades intelectuais (raciocínio e juízo crítico, aptidão para resolver problemas) que o volume de conhecimentos armazenados" (UNESCO, 1993, p. 29). De todo modo, cabe ressaltar os riscos de dar a 
primazia somente à função instrumental dessas capacidades intelectuais em detrimento da formação que possibilite ao sujeito a síntese do pensamento e ação, desenvolvendo quaisquer potencialidades que ele possua.

Em uma formação que possa ser esclarecedora e abrangente, de acordo com Gramsci, o sujeito não deve ser poupado do esforço mental e do trabalho com o pensamento, é preciso oferecer-lhe a ocasião de realizar seu próprio "esforço muscular-nervoso" (2000, p. 51). O currículo do modelo de educação chama por Gramsci (2000) de escola profissional, não considera a lógica formal como algo que precisa ser desenvolvido ou cultivado no homem. Nesse caso, a reflexão como capacidade criadora é negada ao sujeito ao mantê-lo imerso na unilateralidade de currículos favoráveis ao desenvolvimento de habilidades práticoprodutivas. A profunda limitação de tais currículos desconsidera que é do domínio do homem, ou mais, é inerente ao seu ser a liberdade, o pensamento, a criação. No currículo que vise confirmar essa humanidade do sujeito,

não se pode separar o homo faber do homo sapiens. Em suma, todo homem, fora de sua profissão desenvolve uma atividade intelectual, qualquer, ou seja, é um "filósofo", um artista, um homem de gosto, participa de uma concepção do mundo, possui uma linha consciente de conduta moral, contribui assim para manter ou para modificar uma concepção do mundo, isto é, para suscitar novas maneiras de pensar (Gramsci, 2000, p. 53).

Nesse contexto destaca-se o sentido da escola, e consequentemente da universidade, como instituições sociais fundadas na intencionalidade de educar, portanto mediadoras por excelência, da formação dos intelectuais ${ }^{2}$. Na compreensão de Gramsci o processo educativo que possa favorecer também a formação de intelectuais orgânicos e de pessoas autônomas e políticas vincula-se à instituição de um tipo de "escola única inicial de cultura geral, humanista, formativa, que equilibre de modo justo o desenvolvimento da capacidade de trabalhar manualmente, ou tecnicamente, e o desenvolvimento das capacidades de trabalho intelectual" (2000, p. 33). No modelo de escola pensado por Gramsci, primeiramente se deve pensar na formação da cultura geral que propicia ao sujeito não só a instrução, mas também a possibilidade de afirmar sua capacidade de agir na sociedade e na cultura, além de

\footnotetext{
${ }^{2}$ Acerca dos intelectuais, Gramsci demonstra que a sociedade tem suas bases fundadas no universo da cultura e da política, formando várias categorias de intelectuais, embora uma delas seja fundamental, o intelectual orgânico. Esse intelectual nasce do grupo social que "cria para si, ao mesmo tempo, organicamente, uma ou mais camadas de intelectuais que lhe dão homogeneidade e consciência da própria função, não apenas no campo econômico, mas também no social e político" (2000, p. 15). Consiste no sujeito que fala de dentro da classe que ele compõe e produz uma compreensão dessa classe. O intelectual orgânico é o homem concreto, sujeito da possibilidade de intervenção de quaisquer classes sociais nas relações hegemônicas. "Os intelectuais são os 'prepostos' do grupo dominante para o exercício das funções subalternas da hegemonia social e do governo político" (2000, p. 21).
} 
desenvolver certa aptidão na orientação e na iniciativa de acordo com princípios éticos, ligados aos interesses da vida coletiva. Somente na fase posterior da escola, haveria então uma especialização que poderia ser, dentre outras, de caráter científico ou de caráter práticoprodutivo. De qualquer forma, na educação inicial o aluno teria uma experiência formativa que o instigasse à investigação, ao conhecimento e à análise crítica da realidade de modo que as classes menos favorecidas economicamente, não estariam fadadas a uma educação puramente instrumental (2000, p. 38-41).

De acordo com Gramsci, não há nenhum trabalho desprovido do mínimo de qualificação técnica e, ao mesmo tempo, atividade intelectual criadora, mesmo as formas de trabalho mais rudes ou instrumentais, contam com o mínimo de elaboração do pensamento, por isso o autor defende que o homem não é um gorila amestrado, opondo-se à concepção taylorista de que o homem o seria. Nesse sentido todos os homens são intelectuais, mas nem todos eles têm na sociedade a função de intelectual, as categorias formadas para exercer as funções intelectuais provem de todos os grupos e classes sociais, embora, os grupos dominantes sejam providos de mais amplas e complexas possibilidades de formação intelectual.

O desenvolvimento da industrialização no capitalismo gerou necessidades profissionais que levaram à ilusão de que essa escola puramente profissional seria mais democrática. Ironicamente, à medida que tal escola se estratifica, criando novos modelos e formas de alimentar as necessidades tecnológicas do capital, maiores se tornam as disparidades entre as classes sociais (Gramsci, 2000, p. 38-41). Para Gramsci, a educação e a escola comprometidas de algum modo com a formação dos cidadãos, dos quais emergem também os intelectuais orgânicos, instaura a possibilidade de levar as novas gerações à crítica e a criação de sua própria condição histórico-social. Educando a si mesmos como sujeitos capazes de desvelar e compreender o conflito como instrumento de constituição da vida social fundada na democracia, é que o homem pode valorizar as pessoas humanas, e não apenas os interesses de classe e de poder.

o modo de ser do novo intelectual não pode mais consistir na eloqüência, motor exterior e momentâneo dos afetos e das paixões, mas numa inserção ativa na vida prática, como construtor, organizador, "persuasor permanente", já que não apenas orador puro - mas superior ao espírito matemático abstrato; da técnica-trabalho, chega à técnica-ciência e à concepção humanista histórica, sem a qual permanece "especialista" e não se torna "dirigente" (especialista + político)" (Gramsci, 2000, p. 53).

Mas, a elaboração das camadas de intelectuais orgânicos na sociedade não ocorre em um terreno democrático abstrato, desenvolve-se de acordo com movimentos histórico-socias 
concretos. A formação cultural dos indivíduos certamente está vinculada a embates políticos e de classe que rompem com um suposto equilíbrio social, desenrolando-se em meio à tensão que mantém-se pelo pensamento-ação dos sujeitos que movem o diálogo e os embates sociais na cultura, ademais, esse é o papel do intelectual orgânico.

A contribuição da universidade nesse ideal formativo pode ser significativa, destaca-se o ensejo de pensar as contradições sociais como gérmen da transformação, e conceber a formação como possível caminho para o esclarecimento de sujeitos que possam, em condições historicamente construídas, compreender as lacunas de uma educação profissional totalmente acrítica, adaptativa, constituída ideologicamente sob interesses políticos e sociais economicamente totalitários. Para Adorno a reprodução da cultura que forma "consciências coisificadas" (1995, p.119-138) alimenta as possibilidades da falsa experiência formativa empreendida, entre outras, pela industria cultural.

Nessa formação marcada pela banalização do saber e da existência humana, "os meios - e a técnica é um conceito de meios dirigidos a autoconservação da espécie humana - são fetichizados, porque os fins - uma vida humana digna - encontram-se encobertos na consciência das pessoas" (Adorno, 1995 p. 132). Desse modo, os mesmos meios culturais e educativos que podem conduzir o homem à emancipação, podem conduzi-los também à barbárie, dependendo dos princípios e fins que se atribuir à formação.

Em referência a Kant, Adorno evoca a formação cultural e a escola que sejam esclarecedoras e construídas na autonomia, pois, o "esclarecimento é a saída dos homens de sua auto-inculpável menoridade" (Kant apud Adorno, 1995, p. 169). Afinal, que educação e cultura têm sido estas que não conseguem convencer, por meio da razão e do diálogo, o porquê não agir irracionalmente? Adorno previne que o caminho para esse entendimento não é fácil, caso não se queira cair nas armadilhas meramente retóricas desses conceitos.

Da educação e cultura atuais, pode-se dizer com base em suas contradições, que a formação nos cursos de graduação está no campo das lutas sociais, nesse sentido é preciso pensar e defender currículos que possibilitem desvelar as lacunas da concepção de escola e universidade que dá primazia somente aos imperativos do mercado de trabalho. Com mesma intensidade é preciso refletir sobre a universidade como instituição formadora de seres humanos, capazes de pôr a si mesmos e aos outros sujeitos, nunca como um meio ou instrumento para qualquer finalidade que não seja seu próprio projeto de humanidade. Não estaria nesse ponto o ensejo de uma verdadeira cidadania? 
Para isso é necessário refletir no ensino de graduação como instância formativa fértil de possibilidades e fecundidade em relação ao universo da leitura, da história, da língua, literatura, da arte e outros, que podem alargar a consciência das pessoas em relação a tantas outras áreas do saber e da cultura. O alcance humano, político e ético das humanidades quase sempre é ignorado na sociedade produtiva, independente disso, importa considerá-las como fonte de lucidez sobre o sentido provisório do saber que construímos em nós mesmos. Vale acrescentar que o prazer e o compromisso com a busca do saber se transformam em postura diante do mundo, e, partindo do professor, tornar-se sempre referencial para os estudantes que compreendem a importância de sua própria formação.

Se os tempos atuais tendem ao encurtamento de todos os processos educativos que podem ser compreendidos como genuinamente formativos, e ao alargamento daqueles que podem ser chamados de informativos, por outro lado, importa lembrar o compromisso humano, social, e histórico que cabe aos estudantes e aos professores nos cursos de graduação. Nesse sentido, o trabalho de formação das pessoas, ou dos cidadãos, só pode ser conjunto, e para realizá-lo a bom termo é preciso propiciar a discussão acadêmica não somente da formação que temos mas, em especial, daquela que queremos ter. 
Referências

ADORNO, Theodor W. Educação e Emancipação. Rio de Janeiro: Paz e Terra, 1995.

CHAUÍ, Marilena. A universidade operacional. Folha de São Paulo, Caderno Mais, São Paulo, 09/05/1999.

COÊLHO, Ildeu Moreira. O ensino de graduação e currículo. Curitiba: UFPR/PROGRAD, 1994. 2003.

A educação, a cultura e a invenção de uma outra escola. VI EPECO, Campo Grande,

. Ensino, pesquisa e formação de estudantes e professores. In: Revista da PUCCampinas, n.18, jan., 2004.

GRAMSCI, Antonio. Os intelectuais. O princípio Educativo. In: Cadernos do Cárcere, Trad. Carlos Nelson Coutinho, vol.2, Rio de Janeiro: Civilização Brasileira, 2000.

HORKHEIMER, Max \& ADORNO, Theodor W (Org). Temas Básicos de Sociologia. São Paulo: Cultrix, 1973.

UNESCO por FAURE, Edgar. A educação e o destino do homem. In: O Correio da UNESCO. Ano1, N¹. Rio de Janeiro: Fundação Getúlio Vargas, jan., 1993. 